\title{
Cigarette smoking: an important renal risk factor - far beyond carcinogenesis
}

\author{
Orth SR
}

\author{
Division of Nephrology and Hypertension, University Hospital Berne (Inselspital), Berne, Switzerland
}

\begin{abstract}
In recent years, it has become apparent that smoking has a negative impact on renal function, being one of the most important remediable renal risk factors. It has been clearly shown that the risk for high-normal urinary albumin excretion and microalbuminuria is increased in smoking compared to non-smoking subjects of the general population. Data from the Multiple Risk Factor Intervention Trial (MRFIT) indicate that at least in males, smoking increases the risk to reach end-stage renal failure. Smoking is particularly "nephrotoxic" in older subjects, subjects with essential hypertension and patients with preexisting renal disease. Of interest, the magnitude of the adverse renal effect of smoking seems to be independent of the underlying renal disease. Death-censored renal graft survival is decreased in smokers, indicating that smoking also damages the renal transplant. Cessation of smoking has been show to reduce the rate of progression of renal failure both in patients with renal disease or a renal transplant. The mechanisms of smoking-induced renal damage are only partly understood and comprise acute hemodynamic (e.g., increase in blood pressure and presumably intraglomerular pressure) and chronic effects (e.g., endothelial cell dysfunction). Renal failure per se leads to an increased cardiovascular risk. The latter is further aggravated by smoking. Particularly survival of smokers with diabetes mellitus on hemodialysis is abysmal. In the present review article the current state of knowledge about the renal risks of smoking is reviewed. It is the aim of the article to point out that smoking not only increases the risk of renal cell carcinoma or uroepithelial cell carcinoma, but also the risk of a faster decline of renal function. The latter is a relatively new negative aspect which has not been widely recognized.
\end{abstract}

KeY woRDs: Kidney; Renal failure; Progression of renal failure; Dialysis; Cardiovascular death.

\section{INTRODUCTION}

The fact that smoking is a risk factor for renal and uroepithelial cell carcinoma is well known. In the following, I shall review the current knowledge about the less well known adverse renal effects of smoking, which are of particular importance not only for nephrologists but physicians in general. Furthermore, I shall discuss the cardiovacular complications conferred by smoking in the renal patient.

Although earlier reports [1] had indicated that smoking may alter renal function, it was not until 1978 that additional information was published clearly indicating that smoking is a renal risk factor. At that time, Christiansen [2] documented that smoking confers an increased risk for the development of diabetic nephropathy in patients with type 1 diabetes. Thereafter, several studies, mostly performed by diabetologists, confirmed the finding of Christiansen even in patients with type 2 diabetes (for review see[3,4]). It is astonishing that it took 19 years until nephrologists became aware that smoking is a major renal risk factor. At that time the hypothesis was

Received June 20, 2002; Revised Aug. 29, 2002; Accepted Aug. 30, 2002

Correspondence: Stephan R. Orth, M.D., Division of Nephrology and Hypertension, University Hospital of Berne (Inselspital), Freiburgstrasse 10, CH-3010 Berne, Switzerland

Email: stephan.orth@insel.ch

Tel: +41 (31) 632-2130, Fax: +41 (31) 632-9734 
Table 1. Epidemiologic evidence for smoking-induced impairment of renal function

- Dose-dependent increase of urinary albumin excretion rate/proteinuria in cigarette smokers

- Dose-dependent increase of the risk of end-stage renal failure in male cigarette smokers of the general population

- Independent predictor of (micro)albuminuria in patients with primary hypertension

- Most powerful predictor of renal functional decline in patients with primary hypertension

- Increased risk of progression of renal failure in patients with primary renal disease

- In type 1 and type 2 diabetes mellitus: independent risk factor for the onset of microalbuminuria, for progression of microalbuminuria to manifest proteinuria

(i.e., diabetic nephropathy) and for acceleration of the rate of progression of diabetic nephropathy to end-stage renal failure

- Increased risk of renal allograft loss

raised that smoking has a negative impact on renal function, independent of the pre-existing renal disease [5]. Since then, the interest into the topic and the knowledge about the adverse renal effects of smoking has continuously increased. Although large prospective studies are lacking, there is clear epidemiological evidence that smoking has to be considered as one of the most important renal risk factors. This is particularly true for patients with pre-existing renal disease and elderly hypertensive men, but recent evidence suggests that smoking may also impair renal function in patients with apparently normal kidneys. The epidemiological evidence for an adverse renal effect of smoking is summarised in Table 1 and will be discussed in detail (vide infra). Of importance in the context of patient management, there is good evidence that smoking cessation is probably the single most effective measure to retard progression of renal failure [6].

Several potential mechanisms of smoking-induced renal damage have been discussed [7], e.g. increase in blood pressure, alteration of intrarenal hemodynamics, as well as activation of the sympathetic nerve, the renin-angiotensin and the endothelin systems. The pathomechanisms are, however, only partly understood. Recent evidence is available documenting that smoking induces structural alterations of the kidney in both humans and animal models.

Once in end-stage renal failure (ESRF), the failure to discontinue smoking adversely affects the prognosis of patients on renal replacement therapy and patients with a kidney transplant, mainly by increasing the risk of cardiovascular complications. Discontinuation of smoking has been shown to be the single most effective measure to prolong life [8]. This is particularly true in cardiovascular high risk patients such as patients with impaired kidney function.

\section{EFFECT OF SMOKING ON URINARY ALBUMIN/PROTEIN EXCRETION IN SUBJECTS OF THE GENERAL POPULATION WITH APPARENTLY NORMAL KIDNEY FUNCTION}

The nephrotoxic effect of smoking in the general population is documented by a cross-sectional study in 7,476 non-diabetic subjects in Groningen, The Netherlands [9]. The study found that urinary albumin excretion rate correlates to the amount of cigarettes smoked per day. After adjustment for several potential confounding factors, subjects who smoked $<20$ cigarettes/day and subjects who smoked $>20$ cigarettes/day, respectively, showed a dose-dependent association between smoking and high normal albuminuria (relative risk: 1.33 and 1.98, respectively) and microalbuminuria (relative risk: 1.92 and 2.15 , respectively). Interestingly, in a study including 40,619 subjects aged 28-75 years, smoking was associated even with increased urinary albumin concentrations far below the microalbuminuric range [10]. Analysis of a well defined nondiabetic and non-hypertensive subgroup of this latter study revealed that smoking was still independently associated with microalbuminuria [11]. Halimi et al. [12] documented a marked risk of irreversible proteinuria that may occur despite moderate smoking in a study including 28,409 subjects in France. These results from the Netherlands and France have recently been confirmed by a preliminary report documenting an association of smoking and albuminuria in a large cross-sectional probability sample of adults in the USA [13].

\section{EFFECT OF SMOKING ON RENAL FUNCTION IN SUBJECTS OF THE GENERAL POPULATION WITH APPARENTLY NORMAL KIDNEYS}

The question arises whether the increase in albuminuria/proteinuria attributable to smoking is paralleled by an increased risk for renal functional deterioration.

This important issue was addressed in the study of Halimi et al. [12]. Smokers did not exhibit lower creatinine clearance than never smokers. Creatinine clearance was even slightly higher in current smokers, at least in men, even when normotensive and hypertensive subjects were analysed separately. The difference was, however, small, particularly in women. The effect of current smoking on creatinine clearance was reversible upon smoking discontinuation. This observation is compatible with smoking-induced early hyperfiltration. Data from the prospective Multiple Risk Factor Intervention Trial (MRFIT) including 332,544 men, indicate, however, that smoking also increases the risk of ESRF in the general male population [14]: a dose-dependent increase of the relative risk for ESRF was found in smokers as compared to non-smokers (up to 1.69 for heavy smokers) [15]. The increase in risk was 
independent of age, ethnicity, income, blood pressure, diabetes mellitus, prior history of myocardial infarction, or serum-cholesterol. Unfortuantely, the data concerning the relative risk of ESRF attributable to smoking have never been published as a full-size paper. Additional information is only available from a retrospective case-control study analysing data obtained from 4,142 non-diabetic participants of the Cardiovascular Health Study Cohort, all at least 65 years of age, who had two measurements of serum-creatinine performed at least three years apart [16]. In this elderly population the number of cigarettes smoked per day was highly associated with an increase in serum creatinine $>27 \mu \mathrm{mol} / \mathrm{L}(>0.3$ $\mathrm{mg} / \mathrm{dL}$ ). The definition for renal functional deterioration in this study is undoubtedly weak, but smoking may be one of the factors explaining why an impairment of renal function is observed in some, but not all elderly [17, 18]. This assumption is in line with the observation in a sample of 455 adults in Wadena, Minnesota [19], where the decrease in creatinine clearance was greater in ex-smokers and current smokers than in non-smokers.

It can be concluded that (i) smoking increases the risk of albuminuria/proteinuria in the general population and (ii) that there is some evidence indicating that smoking increases the risk of renal functional impairment in the general population, particularly in men and in the elderly. The definition of renal functional deterioration in the studies available is, however, not beyond any doubt and large prospective studies investigating hard end-points, e.g. time to doubling of serum-creatinine, are clearly indicated.

It is noteworthy that the negative impact of smoking on renal function contributes to the increased cardiovascular risk conferred by smoking. An increase in urinary albumin concentrations far below the microalbuminuric range is associated with increased prevalence of established cardiovaskular risk factors and cardiovascular morbidity in the general population [10]. This is true even in non-diabetic and non-hypertensive subjects [11].

\section{ADVERSE RENAL EFFECTS OF SMOKING IN PATIENTS WITH PRIMARY HYPERTENSION}

Proteinuria is found in $4-18 \%$ and albuminuria in $10-25 \%$ of patients with primary hypertension [20,21]. Albuminuria (and even more proteinuria) is an independent predictor of cardiovascular mortality in patients with primary hypertension [21-26].

Smoking emerged as an independent predictor of (micro)albuminuria in several studies which examined otherwise healthy hypertensive subjects. Mimran et al. [27] studied lean patients with primary hypertension and found that the prevalence of microalbuminuria was almost double in smokers compared to non-smokers. Hörner et al. [28] confirmed this finding and found that smoking was the strongest predictor for albuminuria in patients with primary hypertension. The Heart Outcomes Prevention Evaluation (HOPE)-Study [29] documented that smoking was an independent determinant of microalbuminuria in all participants, i.e. non-diabetic and diabetic patients with a high cardiovascular risk profile (approximately $50 \%$ being hypertensive). Furthermore, a recent study [30] found that patients with hypertension and left ventricular hypertrophy smoking $>20$ cigarettes/d had a 1.6-fold higher prevalence of microalbuminuria and a 3.7 -fold higher prevalence of macroalbuminuria than never-smokers.

Important new information has become available concerning the negative impact of smoking on renal functional deterioration in hypertensive patients. Regalado et al. [31] performed a prospective study including 51 patients with primary hypertension for a mean follow-up of 35.5 months. Despite reduction of mean arterial blood pressure from $126.8 \pm 1.3$ $\mathrm{mmHg}$ to $96.5 \pm 1.1 \mathrm{mmHg}$, plasma-creatinine increased from $133 \pm 9 \mu \mathrm{mol} / \mathrm{L}(1.5 \pm 0.1 \mathrm{mg} / \mathrm{dL})$ to $168 \pm 18 \mu \mathrm{mol} / \mathrm{L}(1.9 \pm$ $0.2 \mathrm{mg} / \mathrm{dL}$ ). Factors that independently predicted renal functional decline were smoking, greater initial plasma creatinine level, and black ethnicity. Smoking was by far the most powerful predictor of renal functional deterioration and the only one which is remediable. It is noteworthy that the mean increase in plasma-creatinine for the given observation period is more than can be expected in a representative sample of patients with primary hypertension, so that the data of this well performed, but small prospective study may not be generalisable. Indeed, a large prospective study [32] including 5,730 black and 6,182 non-black hypertensive male subjects (mean age $52.5 \pm 10.2$ years) from the Veterans Administration Hypertension Screening and Treatment Program clinics did not find a relation between smoking and the risk of ESRF during a minimum of 13.9 years of follow-up.

Thus, the issue whether or not smoking increases the rate of progression in patients with primary hypertension remains controversial. Considering the proven effects of smoking on albuminuria/proteinuria it is, however, cautious to conclude that smoking has to be considered as a renal risk factor in hypertensive patients.

\section{ADVERSE RENAL EFFECTS OF SMOKING IN PATIENTS WITH RENAL DISEASE}

The effect of smoking in patients with renal disease is of major interest, because it can be anticipated that this population is particularly susceptible to smoking-induced renal damage. 


\section{Diabetic nephropathy}

The first well documented reports about an increased renal risk in smokers were mostly retrospective studies in patients with type 1 diabetes. It was noted that smokers have a higher risk to develop diabetic nephropathy than non-smokers $[2,33]$.

In the study of Telmer et al. [33] 668 patients with type 1 diabetes were investigated. The prevalence of diabetic nephropathy was significantly higher among "heavy" smokers (>10 cigarettes/d for more than one year) than among "nonheavy" smokers, i.e. $19.2 \%$ versus $12.1 \%$. An increasing frequency of nephropathy was found with increasing cigarette consumption. Diabetic nephropathy was present in $13 \%$ of patients who smoked $<10$ cigarettes/d, but in $>25 \%$ in patients who smoked 30 cigarettes/d. In a cross-sectional study Nórden and Nyberg [34] analysed smoking habits in 47 matched pairs of patients with type 1 diabetes with and without nephropathy. Patients with nephropathy had a significantly higher smoking index (number of cigarettes smoked/d multiplied by number of years smoking) than control patients. There were also significantly more current smokers $(\mathrm{n}=22$ versus $n=14)$, more heavy smokers $(n=20$ versus $n=14)$, and fewer individuals who had never smoked $(\mathrm{n}=9$ versus $\mathrm{n}$ $=18$ ) in the group with nephropathy compared to the group without nephropathy.

Since then, several studies confirmed an increased renal risk in patients with both type 1 and type 2 diabetes who smoke.

Smoking (i) increases the risk to develop microalbuminuria [29, 35-45], (ii) accelerates the rate of progression from microalbuminuria to manifest proteinuria [46-51], and (iii) accelerates progression of renal failure [47, 52-55].

An association between albuminuria/proteinuria and smoking has also been found among children with type 1 diabetes [40] and patients with type 1 diabetes who survived $>30$ 40 years [56, 57]. A genetic predisposition of smokers to develop albuminuria is suggested by the results of the BErgamo NEphrologic DIabetes Complications Trial (BENEDICT). The DD-genotype of the ACE gene was strongly associated with microalbuminuria in smokers [58].

As in non-diabetics, microalbuminuria and overt nephropathy are independent predictors of cardiovascular morbidity and mortality [59], adding to the increased cardiovascular risk conferred by smoking itself.

The magnitude of the effect of smoking on the risk to develop microalbuminuria in patients with diabetes mellitus is not minor. Chase et al. [35] reported that in a group of 359 young subjects with type 1 diabetes the prevalence of borderline $(>7.6 \mu \mathrm{g} / \mathrm{min})$ and abnormal $(>30 \mu \mathrm{g} / \mathrm{min})$ urinary albumin excretion rate was 2.8 -fold higher in smokers than nonsmokers. Similarly, the risk to have microalbuminuria shortterm after the diagnosis of type 2 diabetes is highly increased in current smokers. The odds ratio for the presence of microalbuminuria was 26.3 for current smoking and 3.42 for a $1 \%$ increment in glycosylated $\mathrm{HbA1}$ [44]. Although the confidence intervalls of these latter results were wide, the data indicate the importance of smoking compared to glycemic control as a classic renal risk factor in diabetes mellitus.

Concerning the risk to progress from microalbuminuria to gross proteinuria (>300 mg/d), a prospective study with an observation time of 4 years including 794 patients with type 2 diabetes reported a 2- to 2.5 -fold higher relative risk in heavy smokers than in never-smokers [50].

The acceleration of the rate of progression of renal failure induced by smoking is dramatic. Sawicki et al. [53] calculated the adjusted odds ratio for progression of nephropathy in patients with type 1 diabetes. Progression was defined as an increase in proteinuria $>20 \%$ and/or a reduction of glomerular filtration rate $>20 \%$ after one year of follow-up. The odds ratio was 2.74 for each 10 cigarette pack years. In this study all patients were on intensified insulin and antihypertensive therapy, so that confounding effects of hyperglycemia and hypertension are minimised. In a study of Biesenbach et al. [52] the rate of loss of glomerular filtration rate was higher by a factor of 1.44 and 1.66 in smoking as compared to non-smoking patients with type 1 and type 2 diabetes, respectively. Thus, the influence of smoking on the rate of progression is similar in type 1 and type 2 diabetes.

A recent prospective study with a mean follow-up time of 5.3 years including 33 patients with type 2 diabetes and manifest nephropathy investigated the impact of smoking on progression of renal failure [60]. The initial serum-creatinine was $93 \pm 7 \mu \mathrm{mol} / \mathrm{L}(1.05 \pm 0.08 \mathrm{mg} / \mathrm{dL})$ in smokers $(\mathrm{n}=13)$ and $95 \pm 3 \mu \mathrm{mol} / \mathrm{L}(1.08 \pm 0.03 \mathrm{mg} / \mathrm{dL})$ in non-smokers $(\mathrm{n}=20)$. At the end of observation time, the increase of serum-creatinine was more pronounced in smokers as compared to nonsmokers, i.e. $157 \pm 18 \mu \mathrm{mol} / \mathrm{L}(1.78 \pm 0.2 \mathrm{mg} / \mathrm{dL})$ versus 117 $\pm 4 \mu \mathrm{mol} / \mathrm{L}(1.32 \pm 0.04 \mathrm{mg} / \mathrm{dL})$. This difference was not explained by potential confounding factors and regression anlaysis revealed that smoking was the only parameter that significantly predicted renal functional decline. These data are of particular importance, because blood pressure had been treated according to current standards including an ACE-inhibitor and achieving mean arterial blood pressure of $92 \pm 1 \mathrm{mmHg}$. Thus, smoking seems to remain a renal risk factor despite lowering of blood pressure to the target level using currently recommended therapy, at least in patients with type 2 diabetes. A confirmation of the intreguing finding of a loss of the nephroprotective effect of ACE inhibitortreatment in patients with type 2 diabetes who smoke is needed. Although not comparable, a retrospective case-control study investigating patients with primary renal disease [61] had reported that ACE inhibitor treatment counteracts the 
deleterious effect of smoking on renal function. An explanation why ACE inhibition may protect against smokinginduced renal functional decline may be the improvement of vascular dysfunction in smokers [62]. In vitro data suggest that this effect is partly mediated by scavenging free radicals and by attenuation of the cigarette-induced suppression of nitric oxide production [63]. Due to these considerations and the fact that despite low serum-renin, there is good evidence that the intrarenal angiotensin II production in patients with type 2 diabetes mellitus is increased [64], the above finding of Chuahirun et al. is contraintuitive [60].

If the data of the well performed but small study by Chuahiran et al. can be confirmed, it can be expected that smoking also counteracts the nephroprotective effect of blood pressure lowering including an ACE-inhibitor in patients with type 1 diabetes. This assumption is based on the fact that the course of diabetic nephropathy is identical in type 1 and type 2 diabetes [65] and that the adverse renal effect of smoking on renal functional decline are comparable in type 1 and type 2 diabetes [52].

It is of major clinical importance that smokers are at greater risk to develop type 2 diabetes [66-68]. In a prospective cohort study on 1266 non-diabetic males aged 35-59 years Nakanishi et al. [68] found that the relative risk to develop impaired fasting glucose during 5 years of observation was 1.62-fold higher in ever-smokers as compared to never-smokers. The relative risk to develop type 2 diabetes was dosedependent: $1-20$ cigarettes $/ \mathrm{d}=1.88$ (CI: 0.71-5.0), 21-30 cigarettes $/ \mathrm{d}=3.02$ (CI: 1.15-7.94), $>31$ cigarettes $/ \mathrm{d}=4.09$ (CI: 1.62-10.29). The increased risk may be related to the fact that smoking aggravates insulin resistance in healthy smokers, at least according to some studies [7].

An interesting issue is the effect of smoking on the risk to develop proliferative retinopathy. Based on a priori considerations, one would expect that the risk is increased in smokers, since damage to the microvascular bed of the kidney, i.e. diabetic nephropathy, is often associated with damage to the microvascular bed of the eye, i.e. proliferative diabetic retinopathy [69-72]. In most [33,71, 73-78] but not all studies $[41,46,79,80]$, no difference in the prevalence of proliferative retinopathy was found between smokers and non-smokers with type 1 or type 2 diabetes. Vascular beds of the retina and the kidney have a different susceptibility for smoking-induced damage. The reasons for this difference are unknown. From the above studies it can be concluded that if smoking has any impact on the risk of onset and progression of diabetic retinopathy, this effect has to be considered as minor.

In summary, there is clear evidence that smoking has adverse effects on the onset and evolution of diabetic nephropathy in type 1 and type 2 diabetes mellitus. Furthermore, the number of cigarettes smoked per day and the number of pack-years of exposure seem to be associated with development of impaired fasting glucose and type 2 diabetes.

\section{Non-diabetic renal disease}

There is no evidence in the literature that smoking induces any type of glomerulonephritis or any systemic disease involving the kidney to begin with [81-84]. Solid evidence has accumulated, however, that smoking is a major renal risk factor in patients with primary renal diseases.

In patients with autosomal dominant polycystic kidney disease (ADPKD) Chapman et al. [85] had found that individuals with established proteinuria had a significantly greater pack-year smoking history than did their nonproteinuric counterparts. Based on this first paper indicating an adverse renal effect of smoking in patients with primary renal disease, we performed a retrospective matched case-control study [61]. This European multicenter study was designed to assess whether smoking in patients with IgA-glomerulonephritis (IgA-GN) and ADPKD increases the risk to progress to ESRF. Because analysis of smoking (given as pack-years; PY) showed no strata inhomogeneity between renal diseases, IgA-GN and ADPKD were pooled for statistical analysis. Due to small sample size and modest average tobacco consumption, the subgroup of women was excluded from further analysis. Table 2 shows the distribution of cigarette smoking in male patients; consumption of cigarettes was subdivided into three categories, i.e., 0-5, 5-15 and >15 PY. The crude estimators for different quantitative levels of smoking document a dosedependent increase in the risk for ESRF in male smokers as compared to non-smokers or moderate smokers (0-5 PY) (Table 2). After adjustment for possible confounders, multivariate analysis revealed that the risk for ESRF was substantially higher in male smokers with no history of ACE inhibitor treatment. In contrast, the odds ratio for ESRF of smokers with a history of ACE inhibitor treatment was not significantly increased (Table 3). Another case-control study confirmed that male patients with glomerulonephritis who smoke are at increased risk of renal function impairment [86].

Since the design of these studies was retrospective, a prospective study would be desirable. A post-hoc analysis of a prospective study, which had originally been performed to evaluate the role of dyslipidemia on the progression of renal failure in 73 patients with primary renal disease found that smoking status at entry was related to the decline in glomerular filtration rate after 3.2 years of follow-up [87]. In patients with chronic glomerulonephritis the loss of glomerular filtration rate was $5.3 \mathrm{~mL} / \mathrm{min} /$ year in heavy smokers, but only 2.5 $\mathrm{mL} / \mathrm{min} / \mathrm{year}$ in non-smokers. Thus, smoking appears to double the rate of progression in patients with chronic glomerulonephritis. These data have to be interpreted with caution, because the level of statistical significance was not reached. 
Table 2. Crude smoking-associated risk of end-stagel renal failure in 144 male patients with IgA-glomerulonephritis or autosomal dominant polycystic kidney disease [61]

\begin{tabular}{|c|c|c|c|c|c|}
\hline Pack-years & $\begin{array}{c}\text { Cases } \\
(\mathrm{n},[\%])\end{array}$ & $\begin{array}{l}\text { Controls } \\
(\mathrm{n},[\%])\end{array}$ & Odds ratio & $\begin{array}{l}\text { 95\%-confidence } \\
\text { intervall }\end{array}$ & p-value* \\
\hline $0-5$ & $26[36]$ & $47[65]$ & 1.0 & - & - \\
\hline $5-15$ & $17[24]$ & $11[15]$ & 3.5 & $1.3-9.6$ & 0.017 \\
\hline$>15$ & $29[40]$ & $14[19]$ & 5.8 & $2.0-17$ & 0.001 \\
\hline
\end{tabular}

* Wald $\chi^{2}$.

Table 3. Smoking-associated risk of end-stage renal failure (stratified for ACE inhibitor treatment and adjusted for systolic blood pressure) in 144 male patients with IgA-glomerulonephritis or autosomal dominant polycystic kidney disease [61]

\begin{tabular}{cccccc}
\hline Pack-years & Odds ratio & $\begin{array}{c}\text { ACE inhibitor } \\
\text { 95\%-confidence inter- } \\
\text { vall }\end{array}$ & p-value* & Odds ratio & $\begin{array}{c}\text { No ACE inhibitor } \\
95 \% \text {-confidence inter- } \\
\text { vall }\end{array}$ \\
\hline$<5$ & 1.0 & - & - & 1.0 & - \\
p-value* & -10.1 & $2.3-45$ & 0.002 \\
\hline
\end{tabular}

* Wald $\chi^{2}$.

This may be due to the short observation time and the small number of patients investigated.

The fact that we [61] and Stengel et al. [86] did not find an adverse effect of smoking on renal function in the small female subgroup is presumably related to the limited sensitivity of the studies; certainly the data do not permit to rule out an adverse effect of smoking on renal prognosis in women. Although speculation, it may be that females, at least prior to menopause, are less affected by the adverse renal effect of smoking. In favor of this hypothesis, one study including 246 patients with type 1 diabetes [88] found no relation between smoking and diabetic nephropathy in the female population (n $=106$ ). In contrast, smoking males had a significantly increased risk to develop nephropathy. A further rational is that a recent biopsy study [89] found structural alterations of the kidney in male but not in female smokers (vide infra).

Only a few data are available concerning the effect of smoking on renal function in systemic diseases involving the kidney, namely lupus nephritis. A retrospective cohort study of 160 patients with a median follow-up of 6.4 years documented that smoking at the time of onset of lupus nephritis was an independent risk factor for more rapid progression to ESRF [90]. Life-table analysis was performed to calculate the median time interval to ESRF. It was 145 months in smokers and in excess of 273 months in nonsmokers. This observation seems pertinent, because the effect of smoking was independent of hypertension and immunosuppressive treatment. These data have, however, not been confirmed in a recent prospective study including 70 consecutive patients with lupus nephritis [91]. In this latter study, the patients were compared to 70 age- and sex-matched controls with systemic lupus erythematosus without evidence of nephropathy. At the last visit of the 10 years of follow-up, $67 \%$ of lupus nephritis patients had nor- mal plasma-creatinine, 24\% had renal failure and 9\% ESRF. Hyperlipidaemia and hypertension at study onset were the only factors associated with development of renal failure. Since no other studies have investigated this issue, the influence of smoking on prognosis of lupus nephritis remains unclear.

The hypothesis that heavy smoking might be a risk factor for the development and/or progression of pauci-immune ANCApositive extracapillary glomerulonephritis has been forwarded [92], but solid data on this topic are missing. Due to the damaging effects of smoking on the vascular endothelium [93], it is conceivable that smoking-induced endothelial cell death and desquamation may predispose to the formation of antibodies against nuclear cell antigens extruded from endothelial cells or endothelial cell adherent polynuclear cells. Studies on this interesting and clinically relevant topic are needed.

As far as systemic diseases are concerned, cigarette smoking appears to be a risk factor for pulmonary complications in two clinical situations, which are of importance for the nephrologist. First, smoking increases the risk for fatal lung disease in hypocomplementemic urticarial vasculitis syndrome (HUVS) [94], a rare illness related to systemic lupus erythematosus. Second, the risk of pulmonary hemorrhage in anti-glomerular basement membrane (GBM)-disease, i.e. for the Goodpasture syndrome, is highly increased in smokers $[95,96]$.

\section{SMOKING AND ATHEROSCLEROTIC RENAL ARTERY STENOSIS/ISCHEMIC NEPHROPATHY}

The prevalence of atherosclerotic renal artery stenosis is increasing in the ageing population and ischemic nephropathy is a significant cause of ESRF in patients over 65 years of age [97]. 
The incidence of renal vascular stenosis increases as the extent of peripheral vascular disease increases [98]. Since the latter is common in smokers, it is not surprising that smokers have a higher risk of critical atherosclerotic renal artery stenosis [99]. Smoking is well known to promote atherogenesis. It is of interest that plasma total homocysteine concentration, a predictor of atherogenic risk, is strongly and dose-dependently related to cigarette smoking $[100,101]$. There is, however, no doubt that other pathogenic mechanisms also play a role.

Hadj-Abdelkader et al. [102] examined elderly hypertensive patients with renal failure by arteriography. A significantly higher proportion of patients with atherosclerotic renal artery stenosis, i.e. $80.5 \%$ were smokers compared to patients without atherosclerotic renal artery stenosis, i.e. $44 \%$. A correlation was found with the number of cigarettes smoked and the exposure time. In a Spanish observational multicenter study 156 elderly patients with bilateral atherosclerotic renal artery stenosis and elevated serum-creatinine concentration were investigated. A high proportion, i.e. $70 \%$ were smokers [103]. As one would expect, the prevalence of smokers is increased both amongst patients with unilateral [104] and bilateral [105] atherosclerotic renal artery stenosis.

Although no reports are available about the rate of progression of renal failure in smokers versus non-smokers with renal artery stenosis/ischemic nephropathy, it is likely that smoking accelerates the course of renal failure. This assumption is based on the consideration that besides progressive narrowing of the renal artery, a combination of hypertensive and atheroembolic damage (i.e., cholesetrol embolism), is likely to contribute to progressive loss of renal function in patients with so-called ischemic nephropathy. Actually, smoking is a risk factor for cholesterol embolism [106-108].

In a group of 89 normotensive, non-diabetic elderly subjects with different degrees of peripheral atherosclerosis and no clinical signs of ischemic nephropathy, renovascular hypertension or other nephropathies, evaluation of renal function and plasma flow revealed that despite normal values for glomerular filtration rate, renal plasma flow declined progressively in parallel with the severity of peripheral atherosclerosis [109]. Stepwise multiple regression showed that the decrease in renal plasma flow was best explained by smoking and LDLcholesterol [109]. Since there was a close association between the severity of extrarenal atherosclerosis and renal hypoperfusion, the authors concluded that the existence of initial ischemic nephropathy may be present in these subjects. These findings implicate that renal function should be assessed in patients with extrarenal atherosclerosis, particularly in those with classic cardiovascular risk factors.

\section{ADVERSE EFFECTS OF SMOKING IN PATIENTS ON RENAL REPLACEMENT THERAPY}

Lower serum albumin concentrations predict increased mortality in hemodialysis patients. According to Wave-1 of the United States Renal Data System Dialysis Morbidity and Mortality special study, baseline serum albumin is significantly lower in active smokers as compared to non-smokers on hemodialysis [110]. It is of note that smoking is a highly significant risk factor of death during the first 90 days on hemodialysis [111]. Conversely, the prevalence of active smokers among long-term survivors on hemodialysis is low (11.8\%) [112].

The analysis of 936 hemodialysis patients enrolled in the baseline phase of the Hemodialysis Study sponsored by the US National Institutes of Health revealed that diabetes and smoking are strongly associated with cardiovascular disease [113]. In a national random sample of new ESRD in the USA $(n=4,025)$, coronary artery disease was present in $38 \%$ of patients [114]. Of the total cohort, $17 \%$ had a history of myocardial infarction and $23 \%$ had angina. Several conventional risk factors, including advancing age, male gender, diabetes mellitus, and smoking, were significantly associated with coronary artery disease. Bypass surgery compared to angioplasty yields better results in patients with ESRF. In this context, it is of importance to be aware of the fact that smoking results in a very poor outcome after bypass surgery. One retrospective study investigating 44 dialysis patients undergoing coronary artery bypass grafting from 1984 to 1997 reported a five-year survival of $0 \%$ for smokers and $83.6 \% \pm 7.6 \%$ for non-smokers [115].

Smoking further adds to the increased mortality in patients with diabetes mellitus on hemodialysis, being an independent risk factor contributing particularly to cardiovascular death $[47,49,116,117]$. In one study, smoking and increasing age in patients with diabetes mellitus were the most important adverse features for outcome at the start of renal replacement therapy [118]. The relative risk for mortality in current cigarette smokers in this latter study was 2.28 .

In dialysed patients with type 1 diabetes smoking has been shown to confer a relative risk for lethal myocardial infarction of 2.6 [119]. In a group of diabetic patients on hemodialysis ( $n$ $=22$ smokers and $\mathrm{n}=30$ non-smokers), most of them having type 2 diabetes, the 5-year survival rate of the smoking patients was significantly decreased, i.e. $9 \%$ versus $37 \%$ in the nonsmoking subjects. Cigarette smokers had higher fibrinogen and systolic blood pressure values. At the endpoint of the study, the incidence of myocardial infarction was significantly higher in the smoking patients (77\% versus 13\%). Cardiovascular events were the most frequent cause of death 
in both patient groups, but were more frequent in smokers (80\% versus 63\%) [120].

Smoking also confers a higher risk for atherosclerotic lesions outside the heart. In a study including 89 patients on hemodialysis and 30 on chronic ambulatory peritoneal dialysis, smoking correlated with the mean internal diameter of carotid arteries, the degree of carotid stenosis and the number of plaques in the carotid arteries [121]. An analysis of data from waves 1, 3 and 4 from the United States Renal Data System Dialysis Morbidity and Mortality Study documented that smoking is independently associated with peripheral vascular disease in hemodialysed patients (odds ratio up to 1.55) [122].

The risk of atrial fibrillation, a frequent arrythmia in hemodialysis patients, appears to be associated to coronary heart disease and may contribute to cardiovascular morbidity and mortality in ESRF [123]. Smoking per se does, however, not seem to be of importance for ventricular premature beats or complex ventricular arrhythmia in hemodialysis patients [124, 125]. Of interest, smoking contributes, at least partly, to the decreased heart rate variability observed in patients with ESRF [126]. Furthermore, it is a risk factor for systolic dysfunction in dialysis patients [127]. As far as left ventricular function is concerned, a study including 217 non-diabetic dialysis and transplant patients revealed that besides high alkaline phosphatase (suggestive of hyperparathyroidism) and high serum creatinine levels (reflecting degree of uremia), smoking was the most significant and independent variable associated with low-output left ventricular failure [128].

According to a study from the U.S.A., which investigated a cohort of 1,572 patients (mean age $57.4 \pm 15.0$ years) who started hemodialysis in 1989, smoking is amongst the strongest predictors of the number of hospital days per year [129]. The major part of these patients were African Americans (63.7\%) and $33 \%$ had diabetes mellitus as the primary cause of ESRF. Apart from cardiovascular and pulmonary complications, the increased number of hospital days per year in smokers on hemodialysis is probably also due to the the increased risk of early and late fistula failure [130].

Concerning patients on continuous peritoneal dialysis, only a few scattered informations about the adverse effects of smoking are available. Of importance, smoking increases the risk of permanent change to hemodialysis due to complications [131]. For non-diabetic patients, age, on treatment serum albumin, and current smoking were significant survival risk factors [132]. Whether smoking is a significant risk factor for the development of peripheral vascular disease in these patients, is controversial $[133,134]$, although there is no plausible reason why it should not be.

In the context of management of the patient on renal replacement therapy, it is of importance that smoking is asso- ciated with incompliance in hemodialysis and peritoneal dialysis patients [135].

\section{ADVERSE EFFECTS OF SMOKING IN PATIENTS WITH A RENAL TRANSPLANT}

Contraintuitively, it has been documented that smoking does not appear to increase the risk of microalbuminuria in patients with a renal transplant [136]. Most studies published to date indicated a lack of correlation of smoking with the development of progressive allograft dysfunction [137, 138].

A recent cohort study of 645 adult renal allograft recipients performed from 1985 to 1995 evaluated the relationship between smoking and graft outcome [139]. Twenty-four percent of recipients $(156 / 645)$ were smokers at the time of transplant evaluation. Of these, $90 \%$ continued to smoke after transplantation! Pretransplant smoking was significantly associated with reduced overall graft and death-censored graft survival. Patients who were smokers at the time of pretransplant evaluation had kidney graft survival of $84 \%, 65 \%$, and $48 \%$ at 1,5 , and 10 years, respectively, compared with graft survival in non-smokers of $88 \%, 78 \%$, and $62 \%(\mathrm{p}=0.007)$. Pretransplant smoking adversely affected death-censored graft survival in recipients of cadaveric $(\mathrm{p}=0.02)$ and of living donor kidneys $(p=0.02)$. Reduced graft survival in pretransplant smokers could not be accounted for by differences in rejection episodes (64\% versus $61 \%$ ). In a multivariate analysis, pretransplant smoking was associated with a relative risk of 2.3 for graft loss. Among patients with a smoking history before transplantation, death-censored graft survival was significantly higher for those who quit smoking before transplant evaluation. Thus, this study documents that cigarette smoking before kidney transplantation contributes significantly to allograft loss, an effect that is not explained by increases in rejection episode or patient death. The finding that smoking cessation before renal transplantation has beneficial effects on graft survival is of major importance for the management of patients with ESRF who are considered for renal transplantation. In a retrospective analysis, current smoking has also been documented to be a risk factors for decreased graft survival in first-time kidney transplant recipients aged $\geq 60$ years [140].

In an ongoing prospective study using the large Collaborative Transplant Study database, the issue is currently adressed by G Opelz (Heidelberg, Germany). A preliminary retrospective analysis of Opelz suggests that smoking by itself adversely affects late graft function, even if corrections are made for cardiovascular death with a functioning graft (personal communication). A similar analysis was performed by the group of LC Paul and yielded the same results [141]. It is 
likely that the final results of these investigations will confirm the data of Sung et al. [139].

The effect of smoking on renal allograft function may depend on the renal disease that has led to ESRF. In patients who had reached ESRF as a result of lupus nephritis, the risk of renal transplant loss was substantially increased in smokers [142]. In this study, smoking demonstrated both the strongest association and the highest relative risk for allograft loss (relative risk 2.5, $\mathrm{p}<0.0001$ ) as compared to the other factors which confered an increased risk for allograft loss, i.e., delayed graft function, acute rejection episodes, and total HLA mismatches. Lupus nephritis accounts only for a small proportion of patients requiring renal transplants, but the above results are of major clinical importance and point to the possibility that the alterations of the immune response reported in smokers [5] may be particularly detrimental in patients with immunoregulatory abnormalities such as systemic lupus erythematosus.

It is of note that an investigation of kidney donor lifestyle factors, including smoking, drinking, drug use, and sexual history, found no significant negative impact on renal allograft survival [143].

The evidence that the risk of death with a functioning graft is increased in patients with a history of cigarette smoking is beyond any doubt. The magnitude of the negative impact of smoking in renal transplant recipients is quantitatively similar to that of diabetes mellitus [144]. A retrospective analysis [145] found a higher rate of cardiovascular death with a functioning graft. This has also been documented in first-time kidney transplant recipients aged $\geq 60$ years [140]. Compared to neveror ex-smokers, the diabetic renal transplant recipient had a significantly increased risk of early death if he smoked during the predialysis phase or after having received his graft [49].

The increase in cardiovascular death is due to the well known atherogenic effects of smoking [146, 147]. Smoking appears to increase the risk for low-output left ventricular failure in patients with a renal transplant [128]. As one would expect, cigarette smoking at the time of transplantation is an independent risk factor for cerebrovascular and peripheral vascular disease in transplanted patients [148]. Smoking posttransplantation is a risk factor for carotid plaques [149] and peripheral vascular occlusive disease [150].

Diabetic transplant recipients are at a high risk for foot pathology leading to amputation. Smoking has a profoundly negative effect on the amputation rate as has an amputation prior to transplantation [151].

Another clinically relevant aspect is the higher incidence of cancer in smokers. In one study, cigarette smoking was associated with an increased risk for cancer, with each 10 pack-years smoked at transplant increasing the risk by 1.12 (1.02-1.21; $\mathrm{p}=$ 0.016) [152]. It has also been reported that smoking increases the risk for squamous cell carcinoma of the skin [153]. Furthermore, exposure to the sun and smoking are risk factors for dysplastic and malignant lip lesions in renal transplant recipients [154].

Finally, smoking increases the risk for osteoporosis in corticosteroid-treated transplant patients (and patients with chronic glomerulonephritis) [155] and favours the development of post-transplant erythrocytosis [156].

\section{POTENTIAL MECHANISMS OF SMOKING-INDUCED RENAL DAMAGE}

Several potential mechanisms of smoking-induced renal damage have been discussed in detail elsewhere [7] and are summarised in Table 4. These include acute effects, particularly sympathetic activation (influencing blood pressure and renal hemodynamics), and chronic effects, particularly endothelial cell dysfunction (diminished nitric oxide availability, diminished endothelial cell-dependent vasodilation, and intimal cell hyperplasia). The precise nature of the nephrotoxic effect of smoking is, however, far from being understood. It will be particularly difficult, probably impossible, to delineate which sub-

Table 4. Potential pathomechanisms of smoking-induced renal injury

\footnotetext{
- Increased sympathetic nerve activity

- Increase of blood pressure and heart rate

- Decreased fall of night-time blood pressure

- Increase of renal vascular resistance leading to a decrease in glomerular filtration rate and renal plasma flow

- Increase of intraglomerular capillary pressure

- Aggravation of hyperfiltration in patients with diabetic nephropathy

- Atherosclerosis of renal arteries and myointimal hyperplasia of the intrarenal arteries and arterioles

- Endothelin-1- and/or angiotensin II-mediated proliferation and matrix accumulation of vascular smooth muscle cells, endothelial cells and mesangial cells

- Tubulotoxic effects with alteration of tubular function

- Toxic effects on endothelial cells

- Oxidative stress

- Increased clotting of platelets

- Impaired lipoprotein and glycosaminoglycan metabolism

- Modulation of the immune response

- Vasopressin-mediated antidiuresis

- Insulin resistance
} 
stance(s) in tobacco smoke is (are) responsible for the adverse renal effects of smoking.

Some pathomechanisms of smoking-induced renal damage, which seem of particular importance, are briefly discussed in the following.

\section{Increase in sympathetic activity and blood pressure}

Since the first decade of the 20th century it has been known that smoking induces a transient increase of BP and heart rate [157]. The increase in $\mathrm{BP}$ and heart rate seems to be related to nicotine per se, since no such changes occur when nicotine-free cigarettes are smoked [158]. Today we know that these acute hemodynamic effects are mediated mainly via sympathetic activation and vasopressin release. In addition, in patients with primary hypertension an increase in cortisol, adrenocorticotrophic hormone (ACTH) and plasma aldosterone concentration has been noted during smoking [7].

Grassi et al. [159] demonstrated that nicotine increases sympathetic activity via direct stimulation of postganglionic sympathetic nerve endings: smoking a single cigarette markedly increased plasma concentrations of norepinephrine and epinephrine in healthy volunteers, whereas postganglionic muscle sympathetic nerve traffic decreased significantly. Thus, nicotine directly stimulates catecholamine release from peripheral sympathetic nerve endings and the adrenal medulla [160]. Increased sympathetic activity may also accelerate progression of renal failure [161]. Thus, it is plausible to assume that a further increase of catecholamine release from peripheral sympathetic nerve endings induced by smoking in subjects with renal disease may damage the kidney via two mechanisms, i.e., indirectly through blood pressure elevation, but also as a direct result of activation of the sympathetic system.

In view of the importance of blood pressure on the evolution of renal disease, the effects of smoking on blood pressure are of considerable interest. Ambulatory BP measurements documented that smoking in parallel with the stimulation of the sympathetic system causes a significant, but transient increase (lasting $\sim 30$ minutes) of blood pressure in healthy [162] and hypertensive subjects [163,164]. This was also found in patients with type $1[165,166]$ and type 2 diabetes [167] or primary renal disease [168].

Smoking also seems to alter the diurnal rhythm of blood pressure. Hansen et al. [169] reported that the night/day ratio of systolic and diastolic blood pressure in healthy smokers was lower than in non-smokers. In one study a derangement of the diurnal rhythm of blood pressure was not found in patients with type 1 diabetes who smoked. In contrast, a preliminary communication [170] documented decreased ratios of daytime to nighttime blood pressure in both smoking healthy volunteers and in subjects with type 1 diabetes. It is probable that the presence or absence of autonomic neuropathy in patients with diabetes mellitus is responsible for these contrasting results. For instance, in patients with type 1 diabetes smoking increases systolic blood pressure only in subjects without autonomic neuropathy [166].

\section{Alteration of intrarenal hemodynamics}

Ritz et al. [168] performed a study in healthy volunteers with a history of limited cigarette consumption $(<10$ cigarettes/d) to investigate the effects of smoking on the healthy kidney: smoking (as compared to sham-smoking) caused a significant decrease in glomerular filtration rate (GFR), filtration fraction (FF) and renal plasma flow (RPF) as measured by radioisotope infusion clearance. Renovascular resistance increased significantly. The FF is a surrogate marker of glomerular capillary pressure. This parameter decreased in healthy volunteers. At first sight this observation may appear paradoxical, since reduced intraglomerular pressure should provide nephroprotection, but the renal response is apparently different in subjects with and without renal disease. The findings of Ritz et al. concerning GFR and RPF were confirmed by Halimi et al. [171] in non-smokers who chewed a nicotine chewing gum. Interestingly, in this letter study renal vasoconstriction did not occur in smokers. The authors concluded that smokers continue to exhibit the systemic response to nicotine, i.e., an increase in blood pressure and heart rate, but are tolerant to the renal effects of nicotine. The latter was attributed to a compensatory increase of the synthesis of cyclic guanosine monophosphate (cGMP) in the kidney of smokers as indicated by increased urinary excretion. In a cross-sectional study in 30 subjects with no known vascular risk factors other than chronic cigarette smoking and 24 age- and sexmatched non-smokers without any vascular risk factors, Gambaro et al. [172] reported that smokers had a significant reduction of RPF, but normal GFR. Thus, there is no doubt that acute and chronic smoking induces renal functional alterations, which differ slightly according to the experimental setting.

Ritz et al. [168] also compared the renal hemodynamic effects of smoking in volunteers with those in patients with IgA-glomerulonephritis. Whilst the increase in mean arterial pressure and heart rate was similar in patients with IgAglomerulonephritis and volunteers, a significant decrease in GFR and FF was not demonstrable in patients with IgAglomerulonephritis, in contrast to what was seen in volunteers. During smoking, a significant increase in the urinary albu$\mathrm{min} /$ creatinine ratio was noted, further pointing to an adverse effect of smoking on glomerular capillary pressure.

Taken together these findings are consistent with the hypothesis that in patients with glomerular disease, in whom the preglomerular vasculature is presumably vasodilated, smoking-induced vasoconstriction is unable to overcome 


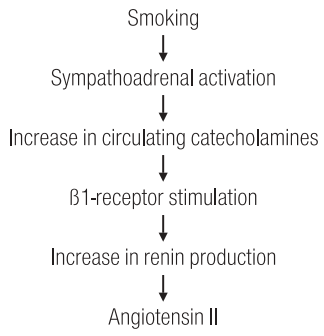

Figure 1. Hypothetical sequence of smoking-induced activation of the renin-angiotensin system via activation of the sympathetic nervous system as one major pathomechanism of smoking-induced renal damage.

vasodilation. As a result one would expect that the increase in systemic pressure is transmitted partially to the glomerular microcirculation, causing acute glomerular hypertension. As reported by Benck et al. [173] pretreatment with the $\alpha$-adrenergic blocker prazosin (compared to placebo) failed to affect the change in renal hemodynamics, whilst pretreatment with the B-blocker atenolol obliterated the renal hemodynamic response. This finding together with the observation of an abrogation of the adverse renal effect of smoking by ACE inhibitor treatment in patients with primary renal disease [61] is consistent with the hypothesis depicted in Figure 1.

\section{Oxidative stress}

Oxidative stress is probably another major player in the genesis of smoking-induced vascular renal injury. Extrusion of glutathione from endothelial cells and activation of the hexose monophosphate shunt, which is necessary to maintain glutathione in the reduced state, point to the presence of oxidative stress, which may be imposed by the free radicals that are present in tobacco smoke [174]. The concentrations of antioxidant enzymes such as glutathione peroxidase, catalase and superoxide dismutase decrease and markers of oxidative stress increase as renal insufficiency advances [175]. The patient with renal failure may thus be particularly susceptible to additional oxidative stress induced by smoking.

\section{Smoking-induced nitric oxide depletion}

The inhibitory effect of smoking on nitric oxide generation may play a critical role in increasing renal vasculature tone. In addition, intrarenal arterial dilation in response to nitroglycerine is significantly impaired in type 2 diabetic patients who smoke [176]. Nitric oxide depletion in smokers may also promote smooth vascular cell and mesangial cell proliferation $[177,178]$. A genetic approach to explain the different susceptibility of individuals to smoking-induced organ damage has been proposed by Wang et al. [179]: the risk of atherogenesis appears to be excessively high in patients who are homozygous for the endothelial nitric oxide synthase 4a (ecNOS4a) gene. This genotype predisposes to endothelial dysfunction and is associated with an increased coronary risk in smokers. Whether a similar genetic susceptibility determines an increased renal risk in smokers is an issue that deserves further investigation.

\section{PATHOHISTOLOGICAL FEATURES OF SMOKING-INDUCED RENAL DAMAGE}

An increase in thickness of walls of arterioles of organs not in direct contact with cigarette smoke, mainly due to fibroelastic intimal proliferation and hyaline thickening in the intima, has been observed in various organs of individuals without renal disease [180, 181], including the kidney [182-184].

In a renal biopsy study, the histological findings of 107 patients (aged $48 \pm 12$ years) with chronic renal failure were assessed by investigating the effect of smoking on glomerulosclerosis and vascular damage [89]. Most of these patients were suffering from glomerular disease with marked proteinuria, only a minority had been treated with an ACE inhibitor at the time of biopsy and blood pressure was not well controlled $(152 / 91 \mathrm{mmHg})$. Smoking was not associated with glomerulosclerosis. As compared to non-smokers, ever-smokers exhibited more severe myointimal hyperplasia. This finding was particularly evident in patients over 50 years of age. In younger patients, a trend toward arteriolar changes was evident for smoking, but it did not reach statistical significance. In females, no correlation was observed. This may due to the fact that women were less likely to be smokers and smoked less than half as many pack-years than did men.

The above study is important, because it documents that ever-smoking increases myointimal hyperplasia in elderly male patients with renal disease. Since hypertension per se seems not to be related to myointimal hyperplasia of intrarenal arterioles [185], the effect of smoking has to be considered as particularly important. The negative finding concerning glomerulosclerosis does not exclude a negative effect of smoking on glomerular structure. Using a more precise method for quantification of renal damage, our group found more severe glomerulosclerosis and tubulointerstitial fibrosis in a rat model of focal-segmental glomerulosclerosis, i.e. the subtotally nephrectomised rat [186]. Whether this is true for humans with non-inflammatory renal disease as well remains to be determined. An increase in glomerular basement width in patients with type 2 diabetes who smoke has been reported in a preliminary study [187]. A rare form of glomerulosclerosis, i.e. idiopathic nodular glomerulosclerosis, has been reported to be observed almost exclusively in smokers. In this latter renal biopsy study including 5,073 patients, 23 cases of idiopathic nodular glomerulosclerosis were diagnosed. Ninety-one percent of these cases were heavy smokers $(52.9+6.9$ pack years) and $96 \%$ had hypertension. Seventeen of the patients 
were followed-up and 6 reached ESRF after a mean of 8.7 months. Importantly, cessation of smoking significantly improved renal prognosis.

\section{REVERSIBILITY OF SMOKING- INDUCED RENAL DAMAGE}

The above observation in patients with idiopathic nodular glomerulosclerosis or a renal transplant indicate that cessation of smoking may substantially reduce the rate of progression of renal failure. The question arises whether this is also true in patients with common renal diseases.

One study in patients with type 1 diabetes and nephropathy provided convincing evidence in this respect [35]: in patients with adequate control of blood pressure, cessation of smoking significantly decreased urinary albumin excretion, although glycemia was not perfectly controlled. In another study, progression was found in 53\% of current smokers, $33 \%$ of ex-smokers and $11 \%$ of non-smokers [53].

It is plausible to assume that this may also be true in nondiabetic renal disease. Pinto-Sietsma et al. [9] found that the risk of microalbuminuria in non-diabetic subjects is only minor in ex-smokers, but not in current smokers. There is some evidence, however, that smoking-induced decrease in renal plasma flow is not completely reversible after smoking cessation [172].

The present data do not allow to draw a definite conclusion about the magnitude of the renal benefit derived from smoking cessation. There is, however, good evidence indicating that smoking cessation is one of the single most effective measures to retard progression of renal failure.

\section{CONCLUSION}

Smoking is one of the most important remediable renal risk factors. It has a negative impact on renal function even in subjects without apparent renal disease, but the adverse renal effects of smoking are particularly eminent in patients with a diseased kidney. Importantly, the increase in the rate of progression of renal failure attributable to smoking seems to be independent of the underlying renal disease.

Nephrologists have to be aware of two major growing medical problems. First, the increase in the number of patients requiring renal replacement therapy, which is partly due to cigarette smoking. Second, the dramatic increase of deaths related to cigarette smoking. The World Health Organization estimated that world-wide tobacco abuse accounted for 3 million deaths in 1996 and even 10 million deaths are expected for the year 2020 [189].

Besides improvement of renal prognosis, cessation of smoking undoubtedly improves cardiovascular prognosis in the renal patient [6]. Thus, Even if ESRF is reached, smoking should be discontinued. Smoking is the strongest predictor of mortality in type 2 diabetes [6], the fastest growing population reaching ESRF. According to lifetable analyses, smoking cessation prolongs the life of a 45-year-old smoking, hypertensive, diabetic male by $4-5$ years; the treatment of hypertension is estimated to prolong the life of the same individual by only 1 year [190]. Of note, even among people who have a history of heavy smoking, the risk of coronary events can be halved by stopping the habit. This benefit from cessation of smoking is seen regardless of how long or how much a person has previously smoked [191]. It has been stated that "persuading hypertensive patients not to smoke is the single most effective measure we can take to reduce their risk" [192]. According to esimates the risk of myocardial infarction can be reduced by 50 $70 \%$ as a consequence of cessation of smoking. In contrast, the treatment of hypertension results in a reduction of risk of myocardial infarction of "only" $2-3 \%$ for each $1 \mathrm{mmHg}$ decline in diastolic BP [193].

Tobacco control programs with the ultimate goal to reduce tobacco use by young individuals are effective [194]. Besides such important preventive measures, major efforts have to be undertaken to help patients to quit smoking. These include the most effective pharmaceutical smoking cessation approaches known to date, i.e. therapy with sustained-release bupropion and nicotine replacement therapy $[195,196]$.

Management of the renal patient requires information about (i) the magnitude of the renal and cardiovascular risk related to smoking including the benefits from smoking cessation and (ii) application of the above modern therapeutic modalities to increase the success rate in patients willing to stop smoking. To the best of my knowledge, there is no information about the exact pharmacokinetics of sustained-release bupropion in patients with impaired renal function. Apparently, bupropion does not accumulate in renal failure. In contrast, nicotine accumulates in renal failure [197], a fact which has to be acknowledged when treating patients with nicotine replacement therapy. Accumulation of nicotine may limit the success rate of smoking discontinuation in patients with renal failure, because the patient is used to a higher level of "intoxication". Actually, diabetic patients with nephropathy have smoked more and still smoke more than patients without nephropathy [48]. On the other hand, it is plausible to assume that more renal patients than individuals in the general population will stop smoking, because they are afraid of the prospect to progress to ESRF. This assumption of greater compliance in severely ill patients is based on the observation that in subjects receiving intervention to stop smoking one year smoking cessation rate is approximately $35 \%$ in healthy subjects [195] but approximately $70 \%$ in patients after a myocardial infarction [198]. It has to be pointed out that to 
date, no data are available about the success of a modern smoking cessation strategy in renal patients.

\section{ACKNOWLEDGMENT}

This paper is dedicated to Prof. Ed Nelson, first President of the PTID Society and Editor-in-Chief of Tobacco Induced Diseases, who kindly invited me to write this article and sadly passed away recently.

The data given in Tables 2 and 3 are reprinted by permission of Blackwell Publishing, Inc.

\section{NOTE ADDED IN PROOF}

As discussed on page 142, males may be more susceptible to smoking-induced renal damage than females. Recent data strengthen this hypothesis [199]: A population-based, crosssectional study [200] of 11,247 Australian adults revealed that smoking was independently associated with renal impairment in men with an odds ratio of 3.59 , but not in women. Smoking was significantly associated with proteinuria in subjects with high-normal systolic blood pressure, with odds ratios ranging from 3.64 at $131.5 \mathrm{~mm} \mathrm{Hg}$ to 5.76 at $139.5 \mathrm{~mm} \mathrm{Hg}$, and in subjects with high-normal 2-hour glucose levels, with odds ratios ranging from 1.76 at $7.0 \mathrm{mmol} / \mathrm{L}$ to 10.84 at $7.7 \mathrm{mmol} / \mathrm{L}$. Lifetime exposure, but not current level of smoking, correlated with lower estimated glomerular filtration rate and greater urine protein-creatinine ratio. Tozawa et al. [201] investigated a large Japanese population $(\mathrm{n}=5,403)$ and found that smoking conferred a relative risk of 1.28 for developing proteinuria in men, but it did not increase the risk in women.

\section{REFERENCES}

1. Lickint F. Tabak und Organismus. Handbuch der gesamten Tabakkunde. Stuttgart: Hippocrates-Verlag, 1939.

2. Christiansen JS. Cigarette smoking and prevalence of microangiopathy in juvenile-onset insulin-dependent diabetes mellitus. Diabetes Care 1978; 1: 146-149.

3. Mühlhauser I. Cigarette smoking and diabetes: an update. Diabetic Medicine 1994; 11: 336-343.

4. Orth SR. Smoking and the kidney. Journal of the American Society of Nephrology 2002; 13: 1663-1672.

5. Orth SR, Ritz E, Schrier RW. The renal risks of smoking. Kidney International 1997; 51: 1669-1677.

6. Orth SR, Viedt C, Ritz E. Adverse effects of smoking in the renal patient. Tohoku Journal of Experimental Medicine 2001; 194: 1-15.

7. Orth SR. Smoking--a renal risk factor. Nephron 2000; 86: 12-26.

8. Hays JT, Dale LC, Hurt RD, Croghan IT. Trends in smokingrelated diseases. Why smoking cessation is still the best medicine. Postgraduate Medicine 1998; 104: 56-62, 65-56, 71.

9. Pinto-Sietsma SJ, Mulder J, Janssen WM, Hillege HL, de Zeeuw D, de Jong PE. Smoking is related to albuminuria and abnormal renal function in nondiabetic persons. Annals of Internal Medicine 2000; 133: 585-591.
10. Janssen WM, Hillege H, Pinto-Sietsma SJ, Bak AA, De Zeeuw $\mathrm{D}$, de Jong PE. Low levels of urinary albumin excretion are associated with cardiovascular risk factors in the general population. Clinical Chemistry and Laboratory Medicine 2000; 38 : 1107-1110.

11. Hillege HL, Janssen WM, Bak AA, Diercks GF, Grobbee DE, Crijns HJ, Van Gilst WH, De Zeeuw D, De Jong PE. Microalbuminuria is common, also in a nondiabetic, nonhypertensive population, and an independent indicator of cardiovascular risk factors and cardiovascular morbidity. Journal of Internal Medicine 2001; 249: 519-526.

12. Halimi JM, Giraudeau B, Vol S, Caces E, Nivet H, Lebranchu Y, Tichet J. Effects of current smoking and smoking discontinuation on renal function and proteinuria in the general population. Kidney International 2000; 58: 1285-1292.

13. Hogan SL, Colindres RE, Cai J, Coresh J. Association of smoking with albuminuria in a cross-sectional probability sample of U.S. adults. Journal of the American Society of Nephrology 2001; 12: 209A.

14. Klag MJ, Whelton PK, Randall BL, Neaton JD, Brancati FL, Ford CE, Shulman NB, Stamler J. Blood pressure and endstage renal disease in men. The New England Journal of Medicine1996; 334: 13-18.

15. Whelton PK, Randall B, Neaton J, Stamler J, Brancati FL, Klag MJ. Cigarette smoking and ESRD incidence in men screened for the MRFIT. Journal of the American Society of Nephrology 1995; 6: 408a.

16. Bleyer AJ, Shemanski LR, Burke GL, Hansen KJ, Appel RG. Tobacco, hypertension, and vascular disease: risk factors for renal functional decline in an older population. Kidney International 2000; 57: 2072-2079.

17. Lindeman RD, Tobin J, Shock NW. Longitudinal studies on the rate of decline in renal function with age. Journal of the American Geriatric Society 1985; 33: 278-285.

18. Fliser D, Franek E, Ritz E. Renal function in the elderly--is the dogma of an inexorable decline of renal function correct? Nephrology Dialysis Transplantation 1997; 12: 1553-1555.

19. Goetz FC, Jacobs DR, Jr., Chavers B, Roel J, Yelle M, Sprafka JM. Risk factors for kidney damage in the adult population of Wadena, Minnesota. A prospective study. American Journal of Epidemiology 1997; 145: 91-102.

20. Ritz E, Nowicki M, Fliser D, Hörner D, Klimm HP. Proteinuria and hypertension. Kidney International Supplement 1994; 47: S76-80.

21. Mimran A, Ribstein J, Du Cailar G. Microalbuminuria in essential hypertension. Current Opinion in Nephrology and Hypertension 1999; 8: 359-363.

22. Luft FC. Microalbuminuria and essential hypertension: renal and cardiovascular implications. Current Opinion in Nephrology and Hypertension 1997; 6: 553-557.

23. Agewall S, Wikstrand J, Ljungman S, Fagerberg B. Usefulness of microalbuminuria in predicting cardiovascular mortality in treated hypertensive men with and without diabetes mellitus. Risk Factor Intervention Study Group. American Journal of Cardiology 1997; 80: 164-169.

24. Jager A, Kostense PJ, Ruhe HG, Heine RJ, Nijpels G, Dekker JM, Bouter LM, Stehouwer CD. Microalbuminuria and 
peripheral arterial disease are independent predictors of cardiovascular and all-cause mortality, especially among hypertensive subjects: five-year follow-up of the Hoorn Study. Arteriosclerosis Thrombosis and Vascular Biology 1999; 19: 617-624.

25. Jensen JS, Feldt-Rasmussen B, Strandgaard S, Schroll M, Borch-Johnsen K. Arterial hypertension, microalbuminuria, and risk of ischemic heart disease. Hypertension 2000; 35: 898903.

26. Ruilope LM, van Veldhuisen DJ, Ritz E, Lüscher TF. Renal function: the Cinderella of cardiovascular risk profile. Journal of the American College of Cardiology 2001; 38: 1782-1787.

27. Mimran A, Ribstein J, DuCailar G, Halimi JM. Albuminuria in normals and essential hypertension. Journal of Diabetes Complications 1994; 8: 150-156.

28. Hörner D, Fliser D, Klimm HP, Ritz E. Albuminuria in normotensive and hypertensive individuals attending offices of general practitioners. Journal of Hypertension 1996; 14: 655660.

29. Gerstein HC, Mann JF, Pogue J, Dinneen SF, Halle JP, Hoogwerf B, Joyce C, Rashkow A, Young J, Zinman B, Yusuf S. Prevalence and determinants of microalbuminuria in highrisk diabetic and nondiabetic patients in the Heart Outcomes Prevention Evaluation Study. The HOPE Study Investigators. Diabetes Care 2000; 23 Suppl 2: B35-39.

30. Wachtell K, Olsen MH, Dahlof B, Devereux RB, Kjeldsen SE, Nieminen MS, Okin PM, Papademetriou V, Mogensen CE, Borch-Johnsen K, Ibsen H. Microalbuminuria in hypertensive patients with electrocardiographic left ventricular hypertrophy: The LIFE Study. Journal of Hypertension 2002; 20: 405412.

31. Regalado M, Yang S, Wesson DE. Cigarette smoking is associated with augmented progression of renal insufficiency in severe essential hypertension. American Journal of Kidney Diseases 2000; 35: 687-694.

32. Perry HM, Jr., Miller JP, Fornoff JR, Baty JD, Sambhi MP, Rutan G, Moskowitz DW, Carmody SE. Early predictors of 15year end-stage renal disease in hypertensive patients. Hypertension 1995; 25: 587-594.

33. Telmer S, Christiansen JS, Andersen AR, Nerup J, Deckert T. Smoking habits and prevalence of clinical diabetic microangiopathy in insulin-dependent diabetics. Acta Medica Scandinavica 1984; 215: 63-68.

34. Nórden G, Nyberg G. Smoking and diabetic nephropathy. Acta Medica Scandinavica 1984; 215: 257-261.

35. Chase HP, Garg SK, Marshall G, Berg CL, Harris S, Jackson WE, Hamman RE. Cigarette smoking increases the risk of albuminuria among subjects with type I diabetes. Journal of the American Medical Association 1991; 265: 614-617.

36. Risk factors for development of microalbuminuria in insulin dependent diabetic patients: a cohort study. Microalbuminuria Collaborative Study Group, United Kingdom. British Medical Journal 1993; 306: 1235-1239.

37. Corradi L, Zoppi A, Tettamanti F, Malamani G, Lazzari P, Fogari R. Association between smoking and micro-albuminuria in hypertensive patients with type 2 diabetes mellitus.
Journal of Hypertension Supplement 1993; 11 Suppl 5: S190191.

38. Olivarius Nde F, Andreasen AH, Keiding N, Mogensen CE. Epidemiology of renal involvement in newly-diagnosed middle-aged and elderly diabetic patients. Cross-sectional data from the population-based study "Diabetes Care in General Practice", Denmark. Diabetologia 1993; 36: 1007-1016.

39. Almdal T, Norgaard K, Feldt-Rasmussen B, Deckert T. The predictive value of microalbuminuria in IDDM. A five-year follow-up study. Diabetes Care 1994; 17: 120-125.

40. Couper JJ, Staples AJ, Cocciolone R, Nairn J, Badcock N, Henning P. Relationship of smoking and albuminuria in children with insulin-dependent diabetes. Diabetic Medicine 1994; 11: 666-669.

41. Chaturvedi N, Stephenson JM, Fuller JH. The relationship between smoking and microvascular complications in the EURODIAB IDDM Complications Study. Diabetes Care 1995; 18: 785-792.

42. Savage S, Nagel NJ, Estacio RO, Lukken N, Schrier RW. Clinical factors associated with urinary albumin excretion in type II diabetes. American Journal of Kidney Diseases 1995; 25: 836-844.

43. Bruno G, Cavallo-Perin P, Bargero G, Borra M, Calvi V, D'Errico N, Deambrogio P, Pagano G. Prevalence and risk factors for micro- and macroalbuminuria in an Italian population-based cohort of NIDDM subjects. Diabetes Care 1996; 19: 43-47.

44. Keller CK, Bergis KH, Fliser D, Ritz E. Renal findings in patients with short-term type 2 diabetes. Journal of the American Society of Nephrology 1996; 7: 2627-2635.

45. Renal involvement in type 1 (IDDM) diabetes in Spain. ESTUDIO DIAMANTE. Diabetes Research and Clinical Practice 1997; 38: 129-137.

46. Mühlhauser I, Sawicki P, Berger M. Cigarette-smoking as a risk factor for macroproteinuria and proliferative retinopathy in type 1 (insulin-dependent) diabetes. Diabetologia 1986; 29: 500-502.

47. Stegmayr B, Lithner F. Tobacco and end stage diabetic nephropathy. British Medical Journal (Clinical Research ED.) 1987; 295: 581-582.

48. Nórden G. Diabetic nephropathy. A clinical study of risk factors in type-I diabetes mellitus. Scandinavian Journal of Urology and Nephrology 1988; Suppl 116: 1-76.

49. Stegmayr BG. A study of patients with diabetes mellitus (type 1) and end-stage renal failure: tobacco usage may increase risk of nephropathy and death. Journal of Internal Medicine 1990; 228: 121-124.

50. Klein R, Klein BE, Moss SE. Incidence of gross proteinuria in older-onset diabetes. A population-based perspective. Diabetes 1993; 42: 381-389.

51. Klein R, Klein BE, Moss SE, Cruickshanks KJ. Ten-year incidence of gross proteinuria in people with diabetes. Diabetes 1995; 44: 916-923.

52. Biesenbach G, Janko O, Zazgornik J. Similar rate of progression in the predialysis phase in type I and type II diabetes mellitus. Nephrology Dialysis Transplantation 1994; 9: 1097-1102. 
53. Sawicki PT, Didjurgeit U, Mühlhauser I, Bender R, Heinemann L, Berger M. Smoking is associated with progression of diabetic nephropathy. Diabetes Care 1994; 17: 126-131.

54. Biesenbach G, Grafinger P, Janko O, Zazgornik J. Influence of cigarette-smoking on the progression of clinical diabetic nephropathy in type 2 diabetic patients. Clinical Nephrology 1997; 48: 146-150.

55. Yokoyama H, Tomonaga O, Hirayama M, Ishii A, Takeda M, Babazono T, Ujihara U, Takahashi C, Omori Y. Predictors of the progression of diabetic nephropathy and the beneficial effect of angiotensin-converting enzyme inhibitors in NIDDM patients. Diabetologia 1997; 40: 405-411.

56. Borch-Johnsen K, Nissen H, Henriksen E, Kreiner S, Salling N, Deckert T, Nerup J. The natural history of insulin-dependent diabetes mellitus in Denmark: 1. Long-term survival with and without late diabetic complications. Diabetic Medicine 1987; 4: 201-210.

57. Mackin P, Macleod JM, New JP, Marshall SM. Renal function in long-duration type I diabetes. Diabetes Care 1996; 19: 249251.

58. Perna A, Iordache BE, Bettinaglio P, Ruggenenti P, Noris M, Galbusera A, Caprioli J, Rubis N, Gritti D, Fassi A, Remuzzi G. DD ACE genotype and smoking cluster with high-normal albuminuria: A cross sectional analysis in 1209 normo-albuminuric type 2 diabetics enrolled in the BErgamo NEphrologic DIabetes Complications Trial (BENEDICT). Journal of the American Society of Nephrology 2001; 12: 154A.

59. Rossing P, Hougaard P, Borch-Johnsen K, Parving HH. Predictors of mortality in insulin dependent diabetes: 10 year observational follow up study. British Medical Journal 1996; 313: 779-784.

60. Chuahirun T, Wesson DE. Cigarette smoking predicts faster progression of type 2 established diabetic nephropathy despite ACE inhibition. American Journal of Kidney Diseases 2002; 39: 376-382.

61. Orth SR, Stöckmann A, Conradt C, Ritz E, in collaboration with Ferro M, Kreusser W, Piccoli G, Rambausek M, Roccatello D, Schäfer K, Sieberth HG, Wanner C, Watschinger B, Zucchelli P. Smoking as a risk factor for endstage renal failure in men with primary renal disease. Kidney International 1998; 54: 926-931.

62. Chalon S, Moreno H, Jr., Hoffman BB, Blaschke TF. Angiotensin-converting enzyme inhibition improves venous endothelial dysfunction in chronic smokers. Clinical Pharmacology and Therapeutics 1999; 65: 295-303.

63. Ota Y, Kugiyama K, Sugiyama S, Ohgushi M, Matsumura T, Doi H, Ogata N, Oka H, Yasue H. Impairment of endothelium-dependent relaxation of rabbit aortas by cigarette smoke extract--role of free radicals and attenuation by captopril. Atherosclerosis 1997; 131: 195-202.

64. Price DA, Porter LE, Gordon M, Fisher ND, De'Oliveira JM, Laffel LM, Passan DR, Williams GH, Hollenberg NK. The paradox of the low-renin state in diabetic nephropathy. Journal of the American Society of Nephrology 1999; 10: 23822391.
65. Ritz E, Orth SR. Nephropathy in patients with type 2 diabetes mellitus. The New England Journal of Medicine 1999; 341: 1127-1133.

66. Rimm EB, Chan J, Stampfer MJ, Colditz GA, Willett WC. Prospective study of cigarette smoking, alcohol use, and the risk of diabetes in men. British Medical Journal 1995; 310: 555-559.

67. Perry IJ, Wannamethee SG, Walker MK, Thomson AG, Whincup PH, Shaper AG. Prospective study of risk factors for development of non-insulin dependent diabetes in middle aged British men. British Medical Journal 1995; 310: 560-564.

68. Nakanishi N, Nakamura K, Matsuo Y, Suzuki K, Tatara K. Cigarette smoking and risk for impaired fasting glucose and type 2 diabetes in middle-aged Japanese men. Annals of Internal Medicine 2000; 133: 183-191.

69. Deckert T, Kofoed-Enevoldsen A, Norgaard K, BorchJohnsen K, Feldt-Rasmussen B, Jensen T. Microalbuminuria. Implications for micro- and macrovascular disease. Diabetes Care 1992; 15: 1181-1191.

70. Faronato PP, Maioli M, Tonolo G, Brocco E, Noventa F, Piarulli F, Abaterusso C, Modena F, de Bigontina G, Velussi M, Inchiostro S, Santeusanio F, Bueti A, Nosadini R. Clustering of albumin excretion rate abnormalities in Caucasian patients with NIDDM. The Italian NIDDM Nephropathy Study Group. Diabetologia 1997; 40: 816-823.

71. Wirta O, Pasternack A, Mustonen J, Laippala P, Lahde Y. Retinopathy is independently related to microalbuminuria in type 2 diabetes mellitus. Clinical Nephrology 1999; 51: 329334.

72. Colhoun HM, Lee ET, Bennett PH, Lu M, Keen H, Wang SL, Stevens LK, Fuller JH. Risk factors for renal failure: the WHO Mulinational Study of Vascular Disease in Diabetes. Diabetologia 2001; 44 Suppl 2: S46-53.

73. Segato T, Midena E, Grigoletto F, Zucchetto M, Fedele D, Piermarocchi S, Crepaldi G. The epidemiology and prevalence of diabetic retinopathy in the Veneto region of north east Italy. Veneto Group for Diabetic Retinopathy. Diabetic Medicine 1991; 8 Spec No: S11-16.

74. Moss SE, Klein R, Klein BE. Association of cigarette smoking with diabetic retinopathy. Diabetes Care 1991; 14: 119-126.

75. Chen MS, Kao CS, Chang CJ, Wu TJ, Fu CC, Chen CJ, Tai TY. Prevalence and risk factors of diabetic retinopathy among noninsulin-dependent diabetic subjects. American Journal of Ophthalmology 1992; 114: 723-730.

76. Moss SE, Klein R, Klein BE. Cigarette smoking and ten-year progression of diabetic retinopathy. Ophthalmology 1996; 103: 1438-1442.

77. Janghorbani M, Jones RB, Allison SP. Incidence of and risk factors for proliferative retinopathy and its association with blindness among diabetes clinic attenders. Ophthalmic Epidemiology 2000; 7: 225-241.

78. Keen H, Lee ET, Russell D, Miki E, Bennett PH, Lu M. The appearance of retinopathy and progression to proliferative retinopathy: the WHO Multinational Study of Vascular Disease in Diabetes. Diabetologia 2001; 44 Suppl 2: S22-30.

79. Paetkau ME, Boyd TA, Winship B, Grace M. Cigarette smoking and diabetic retinopathy. Diabetes 1977; 26: 46-49. 
80. Sparrow JM, McLeod BK, Smith TD, Birch MK, Rosenthal AR. The prevalence of diabetic retinopathy and maculopathy and their risk factors in the non-insulin-treated diabetic patients of an English town. Eye 1993; 7: 158-163.

81. Yaqoob M, Bell GM, Percy DF, Finn R. Primary glomerulonephritis and hydrocarbon exposure: a case-control study and literature review. Quarterly Journal of Medicine 1992; 83: 409-418.

82. Merkel F, Pullig O, Marx M, Netzer KO, Weber M. Course and prognosis of anti-basement membrane antibody (antiBM-Ab)-mediated disease: report of 35 cases. Nephrology Dialysis Transplantation 1994; 9: 372-376.

83. Wakai K, Kawamura T, Matsuo S, Hotta N, Ohno Y. Risk factors for IgA nephropathy: a case-control study in Japan. American Journal of Kidney Diseases 1999; 33: 738-745.

84. Hogan SL, Satterly KK, Dooley MA, Nachman PH, Jennette JC, Falk RJ. Silica exposure in anti-neutrophil cytoplasmic autoantibody-associated glomerulonephritis and lupus nephritis. Journal of the American Society of Nephrology 2001; 12: 134-142.

85. Chapman AB, Johnson AM, Gabow PA, Schrier RW. Overt proteinuria and microalbuminuria in autosomal dominant polycystic kidney disease. Journal of the American Society of Nephrology 1994; 5: 1349-1354.

86. Stengel B, Couchoud C, Cenee S, Hemon D. Age, blood pressure and smoking effects on chronic renal failure in primary glomerular nephropathies. Kidney International 2000; 57 : 2519-2526.

87. Samuelsson O, Attman PO. Is smoking a risk factor for progression of chronic renal failure? Kidney International 2000; 58: 2597.

88. Nielsen MM, Hjollund E. Smoking and diabetic microangiopathy. The Lancet 1978; 2: 533-534.

89. Lhotta K, Rumpelt JH, König P, Mayer G, Kronenberg F. Cigarette smoking and vascular pathology in renal biopsies. Kidney International 2002; 61: 648-654.

90. Ward MM, Studenski S. Clinical prognostic factors in lupus nephritis. The importance of hypertension and smoking. Archives of Internal Medicine 1992; 152: 2082-2088.

91. Font J, Ramos-Casals M, Cervera R, Garcia-Carrasco M, Torras A, Siso A, Darnell A, Ingelmo M. Cardiovascular risk factors and the long-term outcome of lupus nephritis. Quarterly Journal of Medicine 2001; 94: 19-26.

92. Sessa A, Meroni M, Battini G, Vaccari M, Giordano F, Torri Tarelli L. Cigarette smoking and pauci-immune extracapillary glomerulonephritis with ANCA-associated idiopathic systemic vasculitis. A retrospective study. Contributions to Nephrology 2000; 130: 103-108.

93. Michael Pittilo R. Cigarette smoking, endothelial injury and cardiovascular disease. International Journal of Experimental Pathology 2000; 81: 219-230.

94. Wisnieski JJ, Baer AN, Christensen J, Cupps TR, Flagg DN, Jones JV, Katzenstein PL, McFadden ER, McMillen JJ, Pick MA, et al. Hypocomplementemic urticarial vasculitis syndrome. Clinical and serologic findings in 18 patients. Medicine (Baltimore) 1995; 74: 24-41.
95. Donaghy M, Rees AJ. Cigarette smoking and lung haemorrhage in glomerulonephritis caused by autoantibodies to glomerular basement membrane. The Lancet 1983; 2: 13901393.

96. Herody M, Duvic C, Noel LH, Nedelec G, Grunfeld JP. Cigarette smoking and other inhaled toxins in anti-GBM disease. Contributions to Nephrology 2000; 130: 94-102.

97. Textor SC, Wilcox CS. Renal artery stenosis: a common, treatable cause of renal failure? Annual Review of Medicine 2001; 52: 421-442.

98. Metcalfe W, Reid AW, Geddes CC. Prevalence of angiographic atherosclerotic renal artery disease and its relationship to the anatomical extent of peripheral vascular atherosclerosis. Nephrology Dialysis Transplantation 1999; 14: 105-108.

99. Appel RG, Bleyer AJ, Reavis S, Hansen KJ. Renovascular disease in older patients beginning renal replacement therapy. Kidney International 1995; 48: 171-176.

100. Abdella N, Mojiminiyi OA, Akanji AO. Homocysteine and endogenous markers of renal function in type 2 diabetic patients without coronary heart disease. Diabetes Research and Clinical Practice 2000; 50: 177-185.

101. Jacques PF, Bostom AG, Wilson PW, Rich S, Rosenberg IH, Selhub J. Determinants of plasma total homocysteine concentration in the Framingham Offspring cohort. American Journal of Clinical Nutrition 2001; 73: 613-621.

102. Hadj-Abdelkader M, Alphonse JC, Boyer L, Younes H, Deteix P. Smoking and atheromatous stenosis of the renal arteries. Archives des Maladies du Coeur et des Vaisseaux 2001; 94: 925-927.

103. Alcazar JM, Marin R, Gomez-Campdera F, Orte L, Rodriguez-Jornet A, Mora-Macia J. Clinical characteristics of ischaemic renal disease. Nephrology Dialysis Transplantation 2001; 16 Suppl 1: 74-77.

104. Jaboureck O, Mounier-Vehier C, Devos P, Lions C, Dequiedt P, Beregi JP, Carre A. Are demographic characteristics of hypertensive patients different with renal artery stenosis? Archives des Maladies du Coeur et des Vaisseaux 2001; 94: 828-833.

105. Shurrab AE, Mamtora H, O'Donoghue D, Waldek S, Kalra PA. Increasing the diagnostic yield of renal angiography for the diagnosis of atheromatous renovascular disease. British Journal of Radiology 2001; 74: 213-218.

106. Scolari F, Tardanico R, Zani R, Pola A, Viola BF, Movilli E, Maiorca R. Cholesterol crystal embolism: A recognizable cause of renal disease. American Journal of Kidney Diseases 2000; 36: 1089-1109.

107. Ribera Pibernat M, Bigata Viscasillas X, Fuentes Gonzalez MJ, Bielsa Marsol I, Ferrandiz Foraster C. Cholesterol embolism disease: study of 16 cases. Revista Clinica Espanola 2000; 200: 659-663.

108. Main J. How important is atheromatous renal artery stenosis as a cause of end-stage renal disease? Seminars in Dialysis 2001; 14: 143-145.

109. Baggio B, Budakovic A, Casara D, Gambaro G, Saladini G, Piccoli A, Verlato F. Renal involvement in subjects with peripheral atherosclerosis. Journal of Nephrology 2001; 14: 286-292. 
110. Leavey SF, Strawderman RL, Young EW, Saran R, Roys E, Agodoa LY, Wolfe RA, Port FK. Cross-sectional and longitudinal predictors of serum albumin in hemodialysis patients. Kidney International 2000; 58: 2119-2128.

111. Khan IH, Catto GR, Edward N, MacLeod AM. Death during the first 90 days of dialysis: a case control study. American Journal of Kidney Diseases 1995; 25: 276-280.

112. Owen WF, Madore F, Brenner BM. An observational study of cardiovascular characteristics of long-term end-stage renal disease survivors. American Journal of Kidney Diseases 1996; 28: 931-936.

113. Cheung AK, Sarnak MJ, Yan G, Dwyer JT, Heyka RJ, Rocco MV, Teehan BP, Levey AS. Atherosclerotic cardiovascular disease risks in chronic hemodialysis patients. Kidney International 2000; 58: 353-362.

114. Stack AG, Bloembergen WE. Prevalence and clinical correlates of coronary artery disease among new dialysis patients in the United States: a cross-sectional study. Journal of the American Society of Nephrology 2001; 12: 1516-1523.

115. Franga DL, Kratz JM, Crumbley AJ, Zellner JL, Stroud MR, Crawford FA. Early and long-term results of coronary artery bypass grafting in dialysis patients. Annals of Thoracic Surgery 2000; 70: 813-819.

116. Foley RN, Culleton BF, Parfrey PS, Harnett JD, Kent GM, Murray DC, Barre PE. Cardiac disease in diabetic end-stage renal disease. Diabetologia 1997; 40: 1307-1312.

117. Akmal M. Hemodialysis is diabetic patients. American Journal of Kidney Diseases 2001; 38: S195-199.

118. Markowitz GS, Lin J, Valeri AM, Avila C, Nasr SH, D’Agati VD. Idiopathic nodular glomerulosclerosis is a distinct clinicopathologic entity linked to hypertension and smoking. Human Pathology 2002; 33: 826-835.

119. Koch M, Thomas B, Tschöpe W, Ritz E. Survival and predictors of death in dialysed diabetic patients. Diabetologia 1993; 36: 1113-1117.

120. Biesenbach G, Zazgornik J. Influence of smoking on the survival rate of diabetic patients requiring hemodialysis. Diabetes Care 1996; 19: 625-628.

121. Malatino LS, Benedetto FA, Mallamaci F, Tripepi G, Zoccali C, Parlongo S, Cutrupi S, Marino C, Panuccio V, Garozzo M, et al. Smoking, blood pressure and serum albumin are major determinants of carotid atherosclerosis in dialysis patients. CREED Investigators. Cardiovascular Risk Extended Evaluation in Dialysis patients. Journal of Nephrology 1999; 12: 256-260.

122. O'Hare AM, Hsu Cy CY, Bacchetti P, Johansen KL. Peripheral Vascular Disease Risk Factors among Patients Undergoing Hemodialysis. Journal of the American Society of Nephrology 2002; 13: 497-503

123. Fabbian F, Catalano C, Lambertini D, Tarroni G, Bordin V, Squerzanti R, Gilli P, Di Landro D, Cavagna R. Clinical characteristics associated to atrial fibrillation in chronic hemodialysis patients. Clinical Nephrology 2000; 54: 234-239.

124. Blumberg A, Hausermann M, Strub B, Jenzer HR. Cardiac arrhythmias in patients on maintenance hemodialysis. Nephron 1983; 33: 91-95.
125. de Lima JJ, Vieira ML, Lopes HF, Gruppi CJ, Medeiros CJ, Ianhez LE, Krieger EM. Blood pressure and the risk of complex arrhythmia in renal insufficiency, hemodialysis, and renal transplant patients. American Journal of Hypertension 1999; 12: 204-208.

126. Steinberg AA, Mars RL, Goldman DS, Percy RF. Effect of end-stage renal disease on decreased heart rate variability. American Journal of Cardiology 1998; 82: 1156-1158, A1110.

127. Parfrey PS, Harnett JD. Clinical aspects of cardiomyopathy in dialysis patients. Blood Purification 1994; 12: 267-276.

128. Parfrey PS, Harnett JD, Griffiths S, Gault MH, Barre PE, Guttmann RD. Low-output left ventricular failure in endstage renal disease. American Journal of Nephrology 1987; 7: 184-191.

129. Rocco MV, Soucie JM, Reboussin DM, McClellan WM. Risk factors for hospital utilization in chronic dialysis patients. Southeastern Kidney Council (Network 6). Journal of the American Society of Nephrology 1996; 7: 889-896.

130. Wetzig GA, Gough IR, Furnival CM. One hundred cases of arteriovenous fistula for haemodialysis access: the effect of cigarette smoking on patency. Australian and New Zealand Journal of Surgery 1985; 55: 551-554.

131. Gokal R, Baillod R, Bogle S, Hunt L, Jakubowski C, Marsh F, Ogg C, Oliver D, Ward M, Wilkinson R. Multi-centre study on outcome of treatment in patients on continuous ambulatory peritoneal dialysis and haemodialysis. Nephrology Dialysis Transplantation 1987; 2: 172-178.

132. Zimmerman SW, Oxton LL, Bidwell D, Wakeen M. Longterm outcome of diabetic patients receiving peritoneal dialysis. Peritoneal Dialysis International 1996; 16: 63-68.

133. Wakeen M, Zimmerman SW. Association between human recombinant EPO and peripheral vascular disease in diabetic patients receiving peritoneal dialysis. American Journal of Kidney Diseases 1998; 32: 488-493.

134. Webb AT, Brown EA. Prevalence of symptomatic arterial disease and risk factors for its development in patients on continuous ambulatory peritoneal dialysis. Peritoneal Dialysis International 1993; 13 Suppl 2: S406-408.

135. Kutner NG, Zhang R, McClellan WM, Cole SA. Psychosocial predictors of non-compliance in haemodialysis and peritoneal dialysis patients. Nephrology Dialysis Transplantation 2002; 17: 93-99.

136. Halimi JM, al-Najjar A, Buchler M, Giraudeau B, Etienne I, Picou S, Marliere J, Nivet H, Lebranchu Y. Microalbuminuria in hypertensive, non-proteinuric renal transplant recipients: role of previous acute rejection episodes and sodium intake. Archives des Maladies du Coeur et des Vaisseaux 2001; 94: 933-936.

137. Hegeman RL, Hunsicker LG. Chronic rejection in renal allografts: importance of cardiovascular risk factors. Clinical Transplantation 1995; 9: 135-139.

138. Cho YW, Terasaki PI, Cecka JM. New variables reported to the UNOS registry and their impact on cadaveric renal transplant outcomes - a preliminary study. Clinical Transplantation 1995: 405-415. 
139. Sung RS, Althoen M, Howell TA, Ojo AO, Merion RM. Excess risk of renal allograft loss associated with cigarette smoking. Transplantation 2001; 71: 1752-1757.

140. Doyle SE, Matas AJ, Gillingham K, Rosenberg ME. Predicting clinical outcome in the elderly renal transplant recipient. Kidney International 2000; 57: 2144-2150.

141. Sijpkens YW, Doxiadis II, De Fijter JW, Mallat MJ, Van Es LA, De Lange P, Zwinderman AH, Westendorp RG, Van Kemenade FJ, Buijn JA, Claas FH, Paul LC. Sharing crossreactive groups of MHC class I improves long-term graft survival. Kidney International 1999; 56: 1920-1927.

142. Stone JH, Amend WJ, Criswell LA. Outcome of renal transplantation in ninety-seven cyclosporine-era patients with systemic lupus erythematosus and matched controls. Arthritis and Rheumatism 1998; 41: 1438-1445.

143. Feduska NJ, Jr. Donor factors in cadaveric renal transplantation. Clinical Transplantation 1993: 351-357.

144. Cosio FG, Falkenhain ME, Pesavento TE, Yim S, Alamir A, Henry ML, Ferguson RM. Patient survival after renal transplantation: II. The impact of smoking. Clinical Transplantation 1999; 13: 336-341.

145. Kasiske BL, Klinger D. Cigarette smoking in renal transplant recipients. Journal of the American Society of Nephrology 2000; 11: 753-759.

146. Ritz E, Schwenger V, Wiesel M, Zeier M. Atherosclerotic complications after renal transplantation. Transplantation International 2000; 13 Suppl 1: S14-19.

147. Kasiske BL. Ischemic heart disease after renal transplantation. Kidney International 2002; 61: 356-369.

148. Kasiske BL, Guijarro C, Massy ZA, Wiederkehr MR, Ma JZ. Cardiovascular disease after renal transplantation. Journal of the American Society of Nephrology 1996; 7: 158-165.

149. Nankivell BJ, Lau SG, Chapman JR, O'Connell PJ, Fletcher JP, Allen RD. Progression of macrovascular disease after transplantation. Transplantation 2000; 69: 574-581.

150. Sung RS, Althoen M, Howell TA, Merion RM. Peripheral vascular occlusive disease in renal transplant recipients: risk factors and impact on kidney allograft survival. Transplantation 2000; 70: 1049-1054.

151. Kalker AJ, Pirsch JD, Heisey D, Sollinger HW, Belzer FO, Knechtle SJ, D'Alessandro AM. Foot problems in the diabetic transplant recipient. Clinical Transplantation 1996; 10: 503 510.

152. Danpanich E, Kasiske BL. Risk factors for cancer in renal transplant recipients. Transplantation 1999; 68: 1859-1864.

153. Ramsay HM, Harden PN, Reece S, Smith AG, Jones PW, Strange RC, Fryer AA. Polymorphisms in glutathione S-transferases are associated with altered risk of nonmelanoma skin cancer in renal transplant recipients: a preliminary analysis. Journal of Investigative Dermatology 2001; 117: 251-255.

154. King GN, Healy CM, Glover MT, Kwan JT, Williams DM, Leigh IM, Worthington HV, Thornhill MH. Increased prevalence of dysplastic and malignant lip lesions in renal-transplant recipients. The New England Journal of Medicine1995; 332: 1052-1057.

155. Joy MS, Neyhart CD, Dooley MA. A multidisciplinary renal clinic for corticosteroid-induced bone disease. Pharmacotherapy 2000; 20: 206-216.
156. Wickre CG, Norman DJ, Bennison A, Barry JM, Bennett WM. Postrenal transplant erythrocytosis: a review of 53 patients. Kidney International 1983; 23: 731-737.

157. Hesse E. Der Einfluss des Rauchens auf den Kreislauf. Deutsches Archiv für Klinische Medizin 1907; 89: 565-575.

158. Aronow WS, Dendinger J, Rokaw SN. Heart rate and carbon monoxide level after smoking high-, low-, and non-nicotine cigarettes. A study in male patients with angina pectoris. Annals of Internal Medicine 1971; 74: 697-702.

159. Grassi G, Seravalle G, Calhoun DA, Bolla GB, Giannattasio C, Marabini M, Del Bo A, Mancia G. Mechanisms responsible for sympathetic activation by cigarette smoking in humans. Circulation 1994; 90: 248-253.

160. Haass M, Kübler W. Nicotine and sympathetic neurotransmission. Cardiovascular Drugs and Therapy 1997; 10: 657665.

161. Orth SR, Amann K, Strojek K, Ritz E. Sympathetic overactivity and arterial hypertension in renal failure. Nephrology Dialysis Transplantation 2001; 16 Suppl 1: 67-69.

162. Minami J, Ishimitsu T, Matsuoka H. Effects of smoking cessation on blood pressure and heart rate variability in habitual smokers. Hypertension 1999; 33: 586-590.

163. Mann SJ, James GD, Wang RS, Pickering TG. Elevation of ambulatory systolic blood pressure in hypertensive smokers. A case-control study. Journal of the American Medical Association 1991; 265: 2226-2228.

164. Groppelli A, Giorgi DM, Omboni S, Parati G, Mancia G. Persistent blood pressure increase induced by heavy smoking. Journal of Hypertension 1992; 10: 495-499.

165. Hansen HP, Rossing K, Jacobsen P, Jensen BR, Parving HH. The acute effect of smoking on systemic haemodynamics, kidney and endothelial functions in insulin-dependent diabetic patients with microalbuminuria. Scandinavian Journal of Clinical and Laboratory Investigation 1996; 56: 393-399.

166. Sawicki PT, Mühlhauser I, Bender R, Pethke W, Heinemann L, Berger M. Effects of smoking on blood pressure and proteinuria in patients with diabetic nephropathy. Journal of Internal Medicine 1996; 239: 345-352.

167. Poulsen PL, Ebbehoj E, Hansen KW, Mogensen CE. Effects of smoking on 24-h ambulatory blood pressure and autonomic function in normoalbuminuric insulin-dependent diabetes mellitus patients. American Journal of Hypertension 1998; 11: 1093-1099.

168. Ritz E, Benck U, Franek E, Keller C, Seyfarth M, Clorius J. Effects of smoking on renal hemodynamics in healthy volunteers and in patients with glomerular disease. Journal of the American Society of Nephrology 1998; 9: 1798-1804.

169. Hansen KW, Pedersen MM, Christiansen JS, Mogensen CE. Night blood pressure and cigarette smoking: disparate association in healthy subjects and diabetic patients. Blood Pressure 1994; 3: 381-388.

170. Barna I, Kempler P, Büki B, de Chatel R. The influence of chronic smoking on the diurnal rhythm of blood pressure in healthy individuals and in insulin dependent diabetic patients. Nephrology Dialysis Transplantation 1996; 11: A80. 
171. Halimi JM, Philippon C, Mimran A. Contrasting renal effects of nicotine in smokers and non-smokers. Nephrology Dialysis Transplantation 1998; 13: 940-944.

172. Gambaro G, Verlato F, Budakovic A, Casara D, Saladini G, Del Prete D, Bertaglia G, Masiero M, Checchetto S, Baggio B. Renal impairment in chronic cigarette smokers. Journal of the American Society of Nephrology 1998; 9: 562-567.

173. Benck U, Clorius JH, Zuna I, Ritz E. Renal hemodynamic changes during smoking: effects of adrenoreceptor blockade. European Journal of Clinical Investigation 1999; 29: 10101018.

174. Noronha-Dutra AA, Epperlein MM, Woolf N. Effect of cigarette smoking on cultured human endothelial cells. Cardiovascular Research 1993; 27: 774-778.

175. Mimic-Oka J, Simic T, Djukanovic L, Reljic Z, Davicevic Z. Alteration in plasma antioxidant capacity in various degrees of chronic renal failure. Clinical Nephrology 1999; 51: 233-241.

176. Matsumoto N, Ishimura E, Taniwaki H, Emoto M, Shoji T, Kawagishi T, Inaba M, Nishizawa Y. Smoking and proteinuria impair vasodilatory response of intrarenal arteries to nitroglycerine in patients with type 2 diabetes mellitus. Nephrology Dialysis Transplantation 2002; 17: 608-613.

177. von der Leyen HE, Gibbons GH, Morishita R, Lewis NP, Zhang L, Nakajima M, Kaneda Y, Cooke JP, Dzau VJ. Gene therapy inhibiting neointimal vascular lesion: in vivo transfer of endothelial cell nitric oxide synthase gene. Proceedings of the National Academy of Science USA 1995; 92: 1137-1141.

178. Shears LL, Kawaharada N, Tzeng E, Billiar TR, Watkins SC, Kovesdi I, Lizonova A, Pham SM. Inducible nitric oxide synthase suppresses the development of allograft arteriosclerosis. Journal of Clinical Investigation 1997; 100: 2035-2042.

179. Wang XL, Sim AS, Badenhop RF, McCredie RM, Wilcken DE. A smoking-dependent risk of coronary artery disease associated with a polymorphism of the endothelial nitric oxide synthase gene. Nature Medicine 1996; 2: 41-45.

180. Auerbach O, Hammond EC, Garfinkel L. Thickening of walls of arterioles and small arteries in relation to age and smoking habits. The New England Journal of Medicine1968; 278: 980984.

181. Auerbach O, Carter HW, Garfinkel L, Hammond EC. Cigarette smoking and coronary artery disease. A macroscopic and microscopic study. Chest 1976; 70: 697-705.

182. Black HR, Zeevi GR, Silten RM, Walker Smith GJ. Effect of heavy cigarette smoking on renal and myocardial arterioles. Nephron 1983; 34: 173-179.

183. Oberai B, Adams CW, High OB. Myocardial and renal arteriolar thickening in cigarette smokers. Atherosclerosis 1984; 52: 185-190.

184. Tracy RE, Malcom GT, Oalmann MC, Newman WP, Guzman MA. Nephrosclerosis, glycohemoglobin, cholesterol, and smoking in subjects dying of coronary heart disease. Modern Pathology 1994; 7: 301-309.

185. Bos WJ, Demircan MM, Weening JJ, Krediet RT, van der Wal AC. Renal vascular changes in renal disease independent of hypertension. Nephrology Dialysis Transplantation 2001; 16: 537-541.
186. Odoni G, Ogata H, Viedt C, Amann K, Ritz E, Orth SR. Cigarette smoke condensate aggravates renal injury in the renal ablation model. Kidney International 2002; 61: 20902098.

187. Budakovic A, Fioretto P, Saller A, Dalla Vestra M, Zotta L, Baggio B. Cigarette smoking and glomerular ultrastructure in type 2 diabetes. Journal of the American Society of Nephrology 2001; 12: 143A.

188. McMillan MA, Briggs JD, Junor BJ. Outcome of renal replacement treatment in patients with diabetes mellitus. British Medical Journal 1990; 301: 540-544.

189. Emmons KM. Smoking cessation and tobacco control: an overview. Chest 1999; 116: 490S-492S.

190. Yudkin JS. How can we best prolong life? Benefits of coronary risk factor reduction in non-diabetic and diabetic subjects. British Medical Journal 1993; 306: 1313-1318.

191. Culleton BF, Wilson PW. Cardiovascular disease: risk factors, secular trends, and therapeutic guidelines. Journal of the American Society of Nephrology 1998; 9: S5-15.

192. Sleight P. Smoking and hypertension. Clinical and Experimental Hypertension 1993; 15: 1181-1192.

193. Manson JE, Tosteson H, Ridker PM, Satterfield S, Hebert P, O'Connor GT, Buring JE, Hennekens $\mathrm{CH}$. The primary prevention of myocardial infarction. The New England Journal of Medicine1992; 326: 1406-1416.

194. Bauer UE, Johnson TM, Hopkins RS, Brooks RG. Changes in youth cigarette use and intentions following implementation of a tobacco control program: findings from the Florida Youth Tobacco Survey, 1998-2000. Journal of the American Medical Association 2000; 284: 723-728.

195. Jorenby DE, Leischow SJ, Nides MA, Rennard SI, Johnston JA, Hughes AR, Smith SS, Muramoto ML, Daughton DM, Doan K, Fiore MC, Baker TB. A controlled trial of sustained-release bupropion, a nicotine patch, or both for smoking cessation. The New England Journal of Medicine1999; 340: 685-691.

196. Jorenby DE. Smoking cessation strategies for the 21st century. Circulation 2001; 104: E51-52.

197. Molander L, Hansson A, Lunell E, Alainentalo L, Hoffmann M, Larsson R. Pharmacokinetics of nicotine in kidney failure. Clinical Pharmacology and Therapeutics 2000; 68: 250-260.

198. Cole TK. Smoking cessation in the hospitalized patient using the transtheoretical model of behavior change. Heart and Lung 2001; 30: 148-158.

199. Orth SR, Ritz E. Adverse effect of smoking on renal function in the general population: Are men at higher risk? American Journal of Kidney Diseases 2002; 40: 864-866.

200. Briganti EM, Branley P, Chadban SJ, Shaw JE, McNeil JJ, Welborn TA, Atkins RC. Smoking is associated with renal impairment and proteinuria in the normal population: the AusDiab kidney study. Australian Diabets, Obesity and Lifestyle Study. American Journal of Kidney Diseases 2002; 40: 704-712.

210. Tozawa M, Iseki K, Iseki C, Oshiro S, Ikemiya Y, Takishita S. Influence of smoking and obesity on the development of proteinuria. Kidney International 2002; 62: 956-962. 
